\title{
UM NOVO CAMINHO DO CONHECIMENTO FILOSÓFICO DE DEUS: HENRIQUE DE GAND, MESTRE ECKHART, DUNS SCOTUS
}

Theo Kobusch*

RESUMO - Na história da recepção e interpretação da metafísica ou da "Filosofia Primeira" segundo Aristóteles, a contribuição de autores como Tomás de Aquino e João Duns Scotus hoje em dia já é bastante conhecida. No entanto, naquelas concepções que tendem a conceber a metafísica como ou fundamentá-la com base numa teoria dos transcendentais, entendendo aquela disciplina, então, ou como onto-teologia ou como ontologia, as contribuições de Henrique de Gand e Mestre Eckhart ainda são pouco conhecidas. $O$ presente estudo versa sobre a doutrina dos transcendentais desses dois autores, com particular apreço pela influência de Henrique de Gand sobre Duns Scotus. PALAVRAS-CHAVE - Henrique de Gand. Mestre Eckhart. João Duns Scotus. Metafísica. Objeto da Metafísica. Transcendentais. Conhecimento de Deus.
ASBTRACT - In the history of the reception and interpretation of the metaphysics or the "First Philosophy" according to Aristotle, the contribution of authors like Thomas Aquinas and John Duns Scotus is nowadays well known. However, in those conceptions which tend to conceive metaphysics as or to ground it on a theory of transcendental concepts, understanding that discipline then either as onto-theology or as ontology, the contributions of Henry of Ghent and Master Eckhart are still little known. The present study focuses on the doctrine of transcendentals of these two authors, with a particular interest on the influence of Henry of Ghent over Duns Scotus.

KEY WORDS - Henry of Ghent. Master Eckhart. John Duns Scotus. Metaphysics. Object of Metaphysics. Transcendentals. Knowledge of God.

\section{A nova ontologia de Henrique de Gand: a dignidade da essência finita}

Nenhum autor modificou mais a ontologia medieval do que Henrique de Gand. Se os séculos XII e XIII foram claramente marcados, por um lado, pela influência da ontologia neoplatônica intermediada especialmente por Agostinho e, por outro, pela tradição da assim chamada ontologia do ato, a qual, partindo do comentário anônimo ao Parmênides, ganhou uma forma representativa na doutrina de Boécio sobre a forma essendi e inquestionavelmente atingiu o ápice da sua carreira na doutrina do ser de Tomás de Aquino, nesse caso a ontologia de Henrique de Gand aparece como 0 começo de uma nova época. Não mais o ato de ser em si infinito, que todos os entes

* Universidade de Bonn, Alemanha.

\begin{tabular}{|l|l|l|l|l|l|}
\hline VERITAS & Porto Alegre & v. 53 & n. 3 & jul./set. 2008 & p. 59-73 \\
\hline
\end{tabular}


finitos realizam a cada vez do seu modo, constitui o centro; também não a inteligibilidade do ente, mas a sua crua determinação como tal, o conteúdo mesmo na sua mera determinação qüididativa: este é o grande tema de Henrique de Gand.

Por isso, o ser qüdidativo é também o objeto principal da metafísica, mesmo se não o único. Afinal, também pertencem ao campo objetivo dessa "ciência universal" - como o próprio Aristóteles, os seus comentadores da Antiguidade Tardia e também Tomás de Aquino sempre acentuaram - as determinações que seguem ao ente imediatamente, que são, portanto, com ele convertíveis, a saber, o uno, o verdadeiro, o bom e outras, as quais Henrique não chama de transcendentais, mas designa como as primeiras e mais gerais determinações.

Aristóteles tinha descrito o ente enquanto ente como o objeto da metafísica. Henrique dá à expressão "enquanto ente" o seguinte sentido: na medida em que ele tem uma natureza ou uma essência. O que, porém, significa ser uma essência, respectivamente, ter uma essência, essa é, para a ontologia, a pergunta pura e simplesmente decisiva. Henrique põe em jogo, para uma determinação mais aproximada daquilo o que uma essência é, uma outra determinação transcendental importante, a saber, a de "coisa", no sentido de uma determinação firme. Res tem um significado que se deduz de ratitudo. Porém, a determinação da coisa nesse sentido é idêntica com a determinação do ser qüididativo ou da essência. "O quanto mais algo... tem em determinação ou firmeza, tanto mais tem ele em entidade"1. Ora, o conceito de "coisa" ainda tem um outro significado, que se deixa deduzir de "reor reris". Uma coisa é também tudo o que é objeto possível de uma opinião humana, em que permanece bastante incerto se ele é um objeto realmente existente, um objeto real-possível ou só um objeto pensado. Esse conceito de "coisa" abrange, portanto, muito mais do que o outro, a saber, tudo desde o mero fictício, como a montanha de ouro ou o hirco-cervo, até a essência divina. Nesse sentido, ele tem de ser entendido, para Henrique, como o "mais geral de todos", ao qual se contrapõe somente o "puro nada", o qual esse mesmo não pode ser nem um objeto possível de um intelecto nem pode jamais obter existência extramental ${ }^{2}$. Contudo, a coisa no sentido mais geral de todos ou, como Henrique também pode dizer, a "coisa tomada em sentido absoluto" (res absolute), não é nenhum meramente pensado, mas define-se a partir da concebibilidade, isto é, a partir da possibilidade de construção conceitual numa alma humana ${ }^{3}$. Por causa disso, Henrique a designa também como a primeira determinação em cada ente finito ${ }^{4}$.

Ela é apreendida como o primeiro e mais geral de todos os elementos de um ente na audição de uma mera designação, numa espécie de "pré-conhecimento" confuso - tal como Henrique o designa com a expressão tirada dos Segundos analíticos -, o qual, mesmo diante da diferença entre ente e não-ente, ainda é indiferente ${ }^{5}$. 0

\footnotetext{
1 Cf. HENRIQUE DE GAND, Summa quaestionum ordinariarum, a. 34, q. 2, ed. Badius, Paris 1520; 175,71.

2 Cf. HENRIQUE DE GAND, Quodl., VII, q. 1 et 2; 26-27).

3 Cf. HENRIQUE DE GAND, Summa, a. 21, q. 4; fol. 127 rO.

4 Cf. HENRIQUE DE GAND, Summa, a. 34, q. 2; 174,41.

5 Cf. HENRIQUE DE GAND, Summa, a. 24, q. 3; fol. 138 vO/P.
} 
que Henrique em absoluto tematiza, sob o título "coisa", como o mais geral, o ser de pensamento e o ser real de um conceito abrangente inseparado, é, por um lado, a retomada da idéia estóica de um "algo" em absoluto - como a encontramos, por exemplo, no conceito de "res" em Sêneca -, por outro, o começo daquela grande tradição que, sob a palavra-chave de determinações "super-transcendentais", deveria fazer do generalíssimo pensável o seu principal objeto (J. Doyle). A relação desse conceito generalíssimo em absoluto com o ser qüididativo, isto é, com a essência em termos de uma coisa como ratitudo, deve ser pensada como uma relação de inclusão: qualquer coisa que for conhecida como uma essência, já inclui em si esse universal super-transcendental.

Se o conceito mais geral é caracterizado sobretudo pela relação com o intelecto finito, nesse caso a relação especial com o intelecto divino é constitutiva para a essência de um ente. Afinal, o ser qüididativo é atribuído a um ente "com base na relação com a forma do exemplar divino", a partir da qual ele adquire a determinação de uma coisa no sentido de ratitudo ${ }^{6}$. Ele é chamado, portanto, de algo como "natureza" ou "essência" com base no fato de que tem um exemplar no ser divino, de modo que pode ser produzido na forma do ser atual. Essa possibilidade e disposição à existência atual é um ser de tipo próprio que é atribuído à essência como tal. Henrique o denomina de "esse essentiae", que se diferencia da própria essência somente por um outro modus significandi - assim como, por exemplo, também o iluminar se diferencia da $\mathrm{luz}^{7}$. Ainda assim, a relação das essências finitas com o intelecto divino, no qual elas estão fundadas de modo determinado no exemplar, é de outro tipo que aquela, por exemplo, entre entia diminuta com o intelecto humano. Afinal, enquanto algo como o hirco-cervo jamais pode ter um ser verdadeiro fora do intelecto e, nesse sentido, jamais "pode ser" - porque não está dada nem a possibilidade material nem a da causa divina eficiente ${ }^{8}-$, atribui-se ao ser qüididativo das essências finitas um "em si" (ad se) essencial, através do qual elas são capacitadas e tornadas aptas - se Deus o quiser "efetivar" - a receber uma existência verdadeira, isto é, fora do intelecto divino, um "esse existentiae".

Ainda que toda essência realmente existente seja criada por Deus, a criação de uma essência (para uma coisa realmente existente) não efetiva "que a essência é uma essência"10. Antes, o conceito de essência expressa uma possibilidade interna que lhe advém com necessidade. Aquilo que "algo é segundo a essência e a natureza" "não pode não ser tal"11. Porque a determinação-tal e a possibilidade internas são, porém, em si necessárias, elas têm "também, necessariamente, a sua correspondência exemplar em Deus" ${ }^{12}$. A coisidade de uma coisa em termos da

6 Cf. HENRIQUE DE GAND, Summa, a. 34, q. 2; fol.174,43.

7 Cf. HENRIQUE DE GAND, Summa, a. 21, q. 3; fol. 126 vH; a. 21, q. 4; fol. 127 rO.

8 Cf. HENRIQUE DE GAND, Summa, a. 30, q. 2; fol. 179 vF.

9 Cf. HENRIQUE DE GAND, Quodl. IX, q. 2; 31,44s.

10 Cf. HENRIQUE DE GAND, Quodl. XI, q. 3; fol. 450 rI.

11 Cf. HENRIQUE DE GAND, Quodl. V, q. 4; fol. 158 vO.

12 Cf. HOERES, W. "Wesen und Dasein bei Heinrich von Gent und Duns Scotus", in: Franziskanische Studien, 47 (1965), p. 158. 
determinação interna (ratitudo) não é ela mesma fundada por essa relação exemplar. Isso, em todo caso, Henrique parece observar naquela famosa formulação segundo a qual "aquilo que não é uma coisa em termos de determinação (res a ratitudine dicta), não é, por assim dizer, coisa alguma pelo fato de não ter nenhuma idéia em Deus; antes, ao contrário, não tem em Deus nenhum exemplar porque em si não é coisa alguma"13. Por outro lado, Henrique, de determinado modo, reduziu tanto 0 impossível como o possível à onipotência divina. A insidiosa formulação em Quodlibet 8 - razão pela qual alguns intérpretes prontamente querem empurrar Henrique para perto do nominalismo ${ }^{14}$ - reza "que não é o caso que Deus não pode criar o impossível pelo fato de que ele não pode ser criado, mas que ele não pode ser criado porque Deus não o pode criar", e que algo correspondente vale também para o possível ${ }^{15}$.

Sem dúvida, Henrique, aqui como em outras passagens semelhantes ${ }^{16}$, somente pode apontar para a correspondência estrita entre o possível ativo e o passivo, o possível subjetivo e o possível objetivo, o poder divino e o mundo das essências: não há nenhum possível que possa ser subtraído à onipotência divina, e nenhum impossível que também não fosse para Deus um impossível. O motivo interno, porém, para a possibilidade de algo reside, por um lado, na sua essência mesma; para a impossibilidade, por outro, na lei de não-contradição, que representa também o limite do poder de criação divino. Tal como pôr em mente a capacidade de pecar e, com isso, a ordem moral representa para Deus antes uma forma de impotência (impotentia), assim também a possibilidade de infração contra a lei de nãocontradição significava a destruição da ordem das essências, sim, a suspensão de toda ordem. Verdadeira onipotência, assim Henrique quer afirmar, é poder de ordem, é poder evitar a confusão e, com isso, a separação do possível e do impossível ${ }^{17}$. 0 mundo do possível, porém, é o mundo das essências. Henrique, por causa disso, também chamou a essência, expressamente, de possibilidade para o ser, e, com efeito, a possibilidade de ser "objetiva", isto é, aquela fundada na potentia obiectiva ${ }^{18}$. Henrique, para sublinhar a independência ontológica, a consistência e a identidade interna da essência, acentuou também a sua invariabilidade interna, muitas vezes com remissão a um apontamento muito citado de Avicena: a eqüinidade não é nenhuma outra coisa que a eqüinidade.

$\mathrm{O}$ que Henrique quer dizer com isso, sem sombra de dúvida em consonância com Avicena, é o seguinte: uma essência como tal está isenta das diferenças entre 0 ser-real extramental e o ser-pensado intramental, entre o universal e o particular, entre a existência atual e a não-existência, ou antes está ontologicamente

13 Cf. HENRIQUE DE GAND, Quodl., VI, q. 3; 49,12s.

14 Cf. PAULUS, J. Henri de Gand. Essai sur les tendances de sa métaphysique. Paris: Vrin, 1938; HONNEFELDER, L. "Possibilien I. Mittelalter", in: J. Ritter und K. Gründer (Hrsg.), Historisches Wörterbuch der Philosophie, Basel/Stuttgart: Schwabe \& Co. Verlag, Band 7, 1989, p. 1130.

15 Cf. HENRIQUE DE GAND, Quodl., VIII, q. 3; fol. 304 vQ.

16 Cf. HENRIQUE DE GAND, Quodl., VI, q. 3; 41-50.

17 Cf. HENRIQUE DE GAND, Quodl., VIII, q. 3.

18 Cf. HENRIQUE DE GAND Quodl., X, q. 7; 185,41s., 189,57, 197,38. 
pré-ordenada a essas diferenças ${ }^{19}$. Com isso, ela é somente aquilo que ela é20. A qüididade pura de uma coisa como a sua auto-identidade invariável é isso que, segundo Henrique, está na base de todos os modos de ser e de consideração. A existência numa coisa particular, o ser conhecido através de conceito ou proposição, o ser abstraído universal e o ser particular de uma coisa, entre outros aspectos, todas essas determinações "advêm" a uma essência que somente é o que ela é, ou seja, ela é isso não em si, mas só num determinado modo. (Esse ser, porém, é um serordenado à existência atual, tanto na forma do ser-existente extramental como também do ser-conhecido atual intramental de um ente). Portanto, todo ente criado é, ontologicamente, composto de três determinações: da coisidade mais geral, que consiste na mera concebibilidade através de um intelecto criado, da coisidade de determinação interna, isto é, da essência, e do ser de existência exterior ${ }^{21}$.

\section{Henrique de Gand e o novo caminho do conhecimento de Deus: os transcendentais}

Henrique de Gand apresentou a grande alternativa para o esboço tomasiano não apenas no campo da ontologia. Também a sua doutrina do conhecimento filosófico de Deus tem de ser concebida como um novo caminho. Enquanto a tradição aristotélico-tomasiana tomava como possível o caminho de um conhecimento a posteriori de Deus, segundo o qual a razão natural concluía, a partir do mundo sensível como um efeito, a existência de uma primeira causa, Henrique proclama também aqui - em nome de Avicena - a grande alternativa: "É possível um outro conhecimento, a priori", o qual, a partir do conceito de um primeiro como de uma causa, consegue pensar toda outra coisa. Esse novo caminho, previamente assinalado por Avicena, consiste em que o ser humano pode conhecer a existência de Deus com base nos conceitos inteligíveis, universais, presentes a ele, de ente, uno, bom e das demais determinações primeiramente conhecidas das coisas. Essas determinações generalíssimas, que estão presentes no espírito humano como algo evidente por si mesmo (per se notum) antes de todo conhecer sensível, são denominadas por Henrique, com o conceito assumido dos franciscanos, "intenções primeiras", enquanto de resto, na vizinhança filosófica, são chamadas de determinações transcendentais.

Os transcendentais, determinações generalíssimas, devem-se, segundo Avicena, a uma "primeira", ou seja, a uma original impressão na alma; elas têm um caráter no sentido moderno - apriorístico, porque elas mesmas não foram produzidas ou deduzidas por alguma coisa ainda mais conhecida e mais geral. Quando, pois, é possibilitado ao ser humano, através desse primeiro conhecido, pensar não somente esse ente especial, não somente o bom e o verdadeiro particulares, mas o ente, 0 bom e o verdadeiro pura e simplesmente, nesse caso tal conhecido não pode ser um que participa num outro, mas tem de possuir o caráter de subsistência, isto é, eles

19 Cf. HENRIQUE DE GAND, Summa, a. 30, q. 4; fol. $171 \mathrm{rB} / \mathrm{C}$.

20 Cf. a sentença de AVICENA, citada em Quodl., VII, q. 1-2; 18,50: "non est nisi id quod est".

21 Cf. HENRIQUE DE GAND, Summa, a. 28, q. 4; fol. 168 rV. 
têm de ser o ser mesmo, o bom mesmo e o verdadeiro mesmo. A esse, porém, chamamos "Deus". Os conceitos transcendentais de ente, uno, verdadeiro e bom, aos quais Henrique também freqüentemente adiciona o de belo, formam, desse modo, uma ponte entre o finito e o infinito, eles são o comum analogamente entre criador $\mathrm{e}$ criatura $^{22}$.

Para essa argumentação, que não se apóia no testemunho dos sentidos, mas nesses conceitos generalíssimos, Henrique se voltou não somente a Avicena, mas também a Agostinho: "Por causa disso é possível, para Avicena e Agostinho, o conhecimento da existência de Deus com base em tais conceitos de determinações [propositionum] gerais"23. Se faz sentido falar de um agostinismo avicenizante na Idade Média, então, neste contexto, fala-se ainda preferencialmente de um caminho especial do conhecimento de Deus ${ }^{24}$. Esse caminho do conhecimento de Deus, segundo Henrique, não parece, pois, ser plenamente diferente daquele outro que se alça no ser que é manifesto aos sentidos. Afinal, também ele tem o seu início a partir do conhecimento da essência criada, na medida em que abstrai da verdade e da bondade desse criado específico, sendo então conhecido o verdadeiro e o bom pura e simplesmente. Por causa disso, também este modo de argumentação para a existência de Deus repousa, de algum modo, no testemunho dos sentidos, bem como, com efeito, também segundo Aristóteles repousam no conhecimento dos sentidos os princípios primeiríssimos, auto-evidentes, na medida em que aquele conhecimento medeia o significado dos conceitos específicos desses princípios ${ }^{25}$.

Com isso, no caso do novo caminho do conhecimento de Deus, é um notável cruzamento de elementos empíricos e apriorísticos que Henrique tem diante dos olhos. Tal como o olho sensível percebe simultaneamente a cor e a luz e, com efeito, julga antes a cor, muito embora sob a condição da luz, assim também o intelecto apreende ao mesmo tempo confusamente a determinação do bem incriado e do criado, ainda que o seu juízo se relacione somente ou primariamente ao bem finito ${ }^{26}$. $\mathrm{E}$, com efeito, oculta-se por detrás desse aparente caos o original da sua abordagem. $\mathrm{O}$ que Henrique em verdade quer dizer é que, em cada puro conhecimento de uma coisa específica criada, isto é, finita, o ser de Deus já é "co-conhecido" (cointelligere). Afinal, em todo conceito determinado já está "implicitamente contido" o conceito mais geral de ente enquanto ente ${ }^{27}$, e todo conhecimento distinto de um particular inclui o conhecimento geral e confuso do uno, do bom e do verdadeiro pura e simplesmente, e mais ainda: ele os pressupõe. Ora, Henrique acentua expressamente

22 Cf. HENRIQUE DE GAND, Summa, a. 24, q. 6; fol. 142 rQ.

23 Cf. HENRIQUE DE GAND, Summa, a. 22, q. 5; fol. 134 rB-vD; a. 25 q. 3; fol. 153 vF.

24 GILSON, E. "Les sources Gréco-Arabes de l'Augustinisme Avicennisant", AHDLMA, 4 (1929), p. 5-149, numa sentença que ficou famosa, fez referência à conexão da filosofia de Avicena com a do cristianismo, em especial a de Agostinho, na Idade Média Latina. De fato, essa conexão existe, mas não deveria ser restringida à doutrina da alma, respectivamente, do intelecto, tal como Gilson parece fazer. Henrique de Gand, autor no qual encontramos a "conexão mais evidente de todas", não é mencionado nesse contexto.

25 Cf. HENRIQUE DE GAND, Summa, a. 22, q. 5; fol. $135 \mathrm{rE;}$ a. 25, q. 3; fol. 153 vF.

26 Cf. HENRIQUE DE GAND, Summa, a. 24, q. 6; fol. 142 vV.

27 Cf. HENRIQUE DE GAND, Summa, a. 24, q. 7; fol. 144 vK. 
que o ser de Deus é co-conhecido, não somente em todo conhecimento de um finito, mas necessariamente tem de ter sido conhecido antes. Tal como os sentidos primeiramente conhecem o indeterminado e confuso, assim também o intelecto conhece de cada coisa sempre "antes por natureza", ainda que nem sempre segundo o tempo, o geral confuso, portanto, antes conhece ser ela um ente em absoluto do que ser ela este ente, antes conhece ser ela um bom do que que ser ela um bom determinado etc. "Ouanto mais indeterminado é um conhecível, tanto mais cedo, por natureza, o nosso intelecto o conhece".

Agora, o conceito de indeterminação é ambígüo. A indeterminação do universal nas coisas particulares, por exemplo, do bom universal, é de tipo privativo, uma vez que ele ainda apresenta uma forma de participação. Em contrapartida, é indeterminação negativa aquela através da qual é primeiramente conhecido o bom puramente como bom subsistente e, com isso, como uma forma do ser divino ${ }^{28}$. Ainda que o nosso conhecimento direcionado aos objetos particulares comece, portanto, com os sentidos, o conhecimento do universal e, sobretudo, do ser divino é "necessariamente" antecedente, de modo que nenhum finito pode ser conhecido na universalidade sem que o ser de Deus seja co-conhecido, mesmo que - assim acrescenta, significativamente, Henrique - o intelecto não "perceba" isso ${ }^{29} . \mathrm{Ou}$, como diz Henrique em outra passagem: todas as determinações gerais das coisas, como no ente, verdadeiro e bom, tu conheces [...] primeiramente a Deus, mesmo se tu não o percebes ${ }^{30}$.

$\mathrm{O}$ que Henrique anunciou diante da posição tomasiana, como o outro caminho no conhecimento de Deus revela-se, assim, como uma teoria de um conhecimento de Deus implícito, ou, mais ainda: de um conhecimento de Deus inconsciente, o qual é prévio a todo conhecimento objetivo concreto. Ora, também o conhecido inconscientemente, ou, como Henrique diz, na terminologia da filosofia da Antiguidade Tardia, o conhecido "de modo despercebido", pertence ao nosso conhecimento. Alguém que com os seus olhos observou algo passageiro, enquanto ao mesmo tempo, porém, no seu espírito refletiu intensamente sobre outra coisa, dará uma resposta negativa à pergunta correspondente sobre ter visto aquele, "porque não se apercebeu dele". O conhecimento discreto é realizado justamente com o perceber, isto é, com atenção ${ }^{31}$. O conhecer confuso do universal, também 0 conhecer do ente pura e simplesmente, do verdadeiro e do bom, é um conhecer sem atenção, um conhecer despercebido e, nesse sentido, inconsciente, mas é, sem dúvida, um elemento do nosso conhecimento. O primeiro conhecimento, pelo intelecto humano, são as determinações transcendentais de ente, uno, verdadeiro, bom etc., mas na sua indeterminação negativa elas são, a saber, as determinações do ser divino. Deus é o primeiro conhecido implicitamente, mas isso a análise dos conceitos gerais produz como resultado só por último. O novo caminho do conhecimento de Deus,

28 Cf. HENRIQUE DE GAND, Summa, a. 24, q. 7; fol. 144 rF-H.

29 Cf. HENRIQUE DE GAND, Summa, a. 22, q. 6; fol. 135 vL/M.

30 Cf. HENRIQUE DE GAND, Summa, a. 24, q. 7; fol. $144 \mathrm{vK}$.

31 Cf. HENRIQUE DE GAND, Summa, a. 24, q. 9; fol. 146 vX. 
que Henrique, com Avicena, chama de conhecimento a priori, que parte da causa, é o descobrir de um já sempre originalmente conhecido.

\section{A metafísica de Mestre Eckhart: doutrina dos transcendentais}

O pensamento de Mestre Eckhart é marcado pelo vínculo com os autores da Patrística. Isso se mostra em especial nos seus comentários bíblicos. Já cedo, Mestre Eckhart organizou essa obra de interpretação - como L. Sturlese mostrou - num contexto completo, a saber, no monumental Opus Tripartitum, que consiste, na sua primeira parte, na colocação das mais gerais proposições, na sua segunda parte, reunião de questões importantes (não conservadas), cuja ordem se orienta na Suma de Tomás de Aquino, e o qual finalmente, na sua terceira parte, abrange os comentários sobre as Escrituras Sagradas e também todas as Prédicas ${ }^{32}$. Uma vez, porém, que a segunda e a terceira parte, segundo afirmação expressa de Eckhart, não podem ser entendidas sem a primeira parte sobre os conceitos gerais, o intérprete moderno tem o dever, se não quiser apresentar de modo falso a intenção de Echkart, de entender tudo o que está contido na obra latina e alemã, no que diz respeito ao conteúdo, sob os sinais da doutrina dos conceitos gerais. Não exclusivamente, mas no essencial, nesta primeira parte da abrangente obra trata-se dos assim chamados transcendentais, isto é, aquelas determinações mais gerais que são convertíveis com o ser, e essas são sobretudo o uno, o verdadeiro e o bom. 0 ente, o uno, o verdadeiro e o bom são as bases ontológicas gerais e as "pressuposições" de toda atividade particular e determinada, de resto e justamente com isso também da concretização do ente, uno, verdadeiro e bom no ser humano ${ }^{33}$. Portanto, o que Eckhart quer de fato alcançar através da concepção do Opus Tripartitum é a unidade de tratado metafísico e prédica, de metafísica dos transcendentais e doutrina da razão, de ser e contato.

A doutrina dos transcendentais de Mestre Eckhart é de uma novidade inaudita. Afinal, ela não é outra coisa que doutrina de Deus. Isso jamais fora ouvido antes, em Erfurt e Straßburg, a saber, que as determinações transcendentais, as quais ainda segundo Tomás de Aquino designam o ens commune de maneira convertível, são atribuídas "propriamente" a Deus e o caracterizam de modo diferente como um comum participado por tudo o mais ${ }^{34}$. O ser como ser ou o ser num sentido absoluto, respectivamente, simples deve, a saber, ser diferenciado daquele ente especial (ens hoc et hoc), e assim também o uno absolutamente do uno determinado, o pura e simplesmente verdadeiro do verdadeiro individual e, finalmente, o bom transcendental de todo bom particular deste mundo. 0 ser próprio, o uno próprio, 0 verdadeiro próprio e o bom próprio não são outra coisa que Deus mesmo. As

32 Cf. MESTRE ECKHART, Prologus generalis in opus tripartitum, n. 14 (LW I 159): "Et iste erit modus totius peris expositionum et sermonum, [...]".

33 Cf. MESTRE ECKHART, In Gen., II 86 (LW I 548); sobre o conceito de "transcendens" cf. Super Eccl., n. 63 (LW II 293): "unum transcendens".

34 Cf. MESTRE ECKHART, In Joh., n. 512 (LW III 443). 
determinações transcendentais são determinações do ser divino. Esse estrito cruzamento entre a doutrina dos transcendentais e a teologia deve ser apreendido no seu significado histórico-filosófico. Afinal, exprime-se aqui a consciência de um novo caminho sobre a problemática de Deus.

Mestre Eckhart tomou conhecimento desse novo caminho possivelmente a partir de Henrique de Gand. Uma proximidade de pensamento com o novo "caminho" descrito por Henrique na sua Summa, em estreita vinculação com Avicena, é inconfundível. Henrique havia proposto, diante do - para os aristotélicos - costumeiro "caminho da demonstração através do manifesto aos sentidos", o "caminho dos conceitos, respectivamente, das proposições gerais, inteligíveis" para 0 conhecimento do divino. Elas não são outra coisa que justamente as proposições gerais sobre o ente, uno e bom, e sobre as determinações mais gerais das coisas primeiramente conhecidas pelo intelecto, através das quais o ser humano, na medida em que desconsidera todo ente, uno e bom determinados (hoc ens, etc.), apreende 0 ente, o uno, o verdadeiro e o bom simplesmente, como subsistente necessariamente ${ }^{35}$. Manifestamente, Mestre Eckhart assumiu esse novo método do conhecimento de Deus descrito pela primeira vez por Henrique de Gand - método que encontra ressonância em muitos franciscanos ${ }^{36}$-, na medida em que ele, nos termos do método euclidiano, que também está na base da Elementatio de Próclo, lança previamente a toda a obra monumental as proposições mais gerais sobre os transcendentais como axiomas ou conceptiones animi, ou ainda koinai ennoiai.

O primeiro desses axiomas auto-evidentes é a proposição "O ser é Deus". Quem sabe o que o ser é propriamente, a saber, a perfeição ou a atualidade mesma não contraível a nenhum determinado, e ainda imutável e generalíssima, e conhece também o significado da expressão "Deus", esse assentirá prontamente a essa proposição como a um princípio em si conhecido. Algo semelhante é válido também para uno, verdadeiro e bom, que resultam do conceito de ser corretamente entendido, porém, "do modo mais imediato", o uno. Afinal, se o ser é a plenitude de toda realidade, nesse caso nada de modo negativo pode ser afirmado dele, antes ele mesmo tem de ser a "negação da negação" e, nesse sentido, o uno. Mestre Eckhart remeteu essa expressão, que não é em absoluto neoplatônica, a um mestre. "Um mestre fala: uno é um negar do negar" ${ }^{37}$. Como foi comprovado por W. Goris, tratase, aqui, de Henrique de Gand, no qual a expressão é comprovável no mesmo sentido $^{38}$. Uma vez que não há nenhuma negação determinada ali onde somente há a negação da negação, ali não pode haver também nenhuma diferenciação. Por isso mesmo, o ser divino é o uno também em termos de diferenciação, o qual justamente

35 Cf. HENRIQUE DE GAND, SUmma a. 22 q. 5, f. 134 rB-135 rE.

${ }^{36}$ Cf. sobre isso KOBUSCH, T. "Gott und die Transzendentalien: Von der Erkenntnis des Inklusiven, Impliziten, Konfusen und Unbewußten", in: M. Pickavé (Hrsg.), Miscellanea Mediaevalia 30 - Die Logik des Transzendentalen, Festschrift für J. A. Aertsen zum 65. Geb., Berlin/New York: Walter de Gruyter, 2003, p. 421-432.

37 Cf. MESTRE ECKHART, Pr. 21 (DW I 361); Prol. Op. prop., n. 15 (LW I 175).

${ }^{38} \mathrm{Cf}$. GORIS, W. Einheit als Prinzip und Ziel: Versuch über die Einheitsmetaphysik des Opus Tripartitum Meiter Eckahrts. Leiden: Brill, 1997, p. 197-206. 
por meio disso se diferencia do reino do diferente e da região da dessemelhança ${ }^{39}$. Aqui, porém, Mestre Eckhart manifestamente assumiu elementos neoplatônicos no seu conceito de uno ${ }^{40}$.

É, pois, de significado decisivo para o caráter total da obra o fato de que Mestre Eckhart não fica parado numa tal teoria abstrata dos transcendentais, segundo a qual o verdadeiramente ente, uno, verdadeiro e bom, são reservados a Deus somente, enquanto todo finito seria o nada, o múltiplo, o não-verdadeiro e o mau. Afinal, ali onde o uno é não há mais ou menos, isso e aquilo, não há nenhuma diferença, nenhum próprio, afinal, o uno é comum a todos. No uno não há nada ruim, nenhum defeito, nenhuma privação, nenhuma divisão, nenhum número, nenhuma pluralidade. Entre as coisas finitas, portanto, parece não poder haver nenhum uno verdadeiramente. 0 que, porém, ocorre como a alma humana? Também aqui vale, primeiramente, o que vale para o mundo das coisas: na medida em que ela busca o "próprio", a "propriedade", na medida em que ela ama isso e aquilo e se fixa no múltiplo, nessa medida Deus, o uno, não mora nela ${ }^{41}$. Mas, aí reside ainda um "pequeno detalhe", o qual, no duplo significado da expressão - platônico e eckhartiano -, ainda tem de ser refletido.

\section{A doutrina de Duns Scotus sobre os transcendentais e sobre o conhecimento de Deus}

\subsection{O conceito unívoco do ente}

Como em Henrique de Gand, também em Duns Scotus o caminho do conhecimento leva do confuso para o distinto $0^{42}$. 0 conhecido confusamente - o qual, para Scotus, além disso deve ser diferenciado do conhecimento de um confuso, isto é, de um todo na sua indeterminação - é aquele universal que nós apreendemos no conhecimento cotidiano de uma coisa e designamos através de um mero nome. 0 conhecido distintamente é, em contrapartida, o universal apreendido na definição da coisa, cujos elementos de conteúdo particulares também são por si apreendidos evidentemente. $\mathrm{O}$ conhecido confusamente, portanto, o conceito da qüididade de uma coisa indicado pelo nome confuso, é, porém, em princípio o conhecido anteriormente diante do conceito distinto.

39 Cf. MESTRE ECKHART, In Joh., n. 99 (LW III 85): "dei proprium est esse indistinctum et ipse sola sua indistinctione distinguitur, creaturae vero proprium est esse distinctum"; semelhantemente também em In Exod., n. 117 (LW II 112).

40 O neoplatonismo concebeu o Uno como o "adiakriyon". Também a dialética de indiferenciação e diferenciação já parece ser conhecida. Cf., por exemplo, PRÓCLO, Theol. Plat. I, 11, ed. H.D. Saffrey et L.G. Westernink, Paris, 1968, 54, 15, ou DAMASCIUS, Traité des Premiers Principes, vol. II, ed. L.G. Westerink/J. Combès, Paris, 1989, p. 116.

41 Cf. MESTRE ECKHART, In Joh., n. 208 (LW III 176).

42 Cf. DUNS SCOTUS, Lectura, I, d. 3, p. 1, q. 1-2, n. 78-79, ed. Vat. XVI: 254. 
O conceito distinto é obtido através de uma "análise" (resolutio) do conhecido confusamente. A análise do conhecido confusamente leva, por fim, ao conceito absolutamente simples de ente, o qual não é posteriormente analisável em outros conceitos, o qual, porém, já está contido por sua vez em todos os conceitos qüididativamente determinados. 0 conceito absolutamente simples de ente, assim obtido, serve como ponto de partida do caminho inverso, que Scotus chama de via divisionis, o desmembramento conceitual através do qual é desdobrada a constituição metafísica das coisas, isto é, as suas determinações qüididativas particulares. 0 conceito de ente é, por isso mesmo, o primeiro conceito conhecível distintamente, muito embora seja, ao mesmo tempo, no sentido de um todo, um confuso conhecido ${ }^{43}$. A metafísica como a disciplina competente para esse conceito é, por isso, por um lado a última na classificação das ciências - como o diz Avicena de modo especialmente claro, mas também já os currículos da Antiguidade Tardia em Atenas e Alexandria -, por outro, porém, é a primeira na ordem do conhecimento distinto ${ }^{44}$.

Contra Henrique e a metafísica dos transcendentais até aqui, Scotus mostra, porém, que, se o conceito de ente e os outros conceitos transcendentais convertíveis com ele - como Scotus acentua claramente em Ord. I d. 3 p. 1 q. 3 n. $135^{45}$ - são "perfeições puras" e se atribuem em suma medida a Deus, eles têm de ser conceitos unívocos. Ente, bom, sabedoria e semelhantes são predicados, portanto, num sentido unívoco de Deus e das coisas criadas ${ }^{46}$. Perfeições puras são, porém, aquelas às quais um imperfeito, por exemplo, "este bom" ou "este verdadeiro", o qual - diferentemente de, por exemplo, "este ser humano" - não contém já em si uma limitação, pode ser reduzido ${ }^{47}$. É, porém, manifesto que Duns Scotus foi levado à teoria do conceito unívoco do ente através do novo caminho no conhecimento metafísico de Deus impulsionado por Avicena e indicado por Henrique, caminho que toma o seu ponto de partida nos transcendentais. Afinal, "toda investigação metafísica sobre Deus procede de tal modo" que ela despe as determinações formais de uma coisa da imperfeição que elas têm no mundo do criado, na medida em que as trata em si e por si, atribuindo-as, na sua forma mais perfeita, a Deus. Isso, porém, não seria possível se o intelecto humano não tivesse um conceito idêntico, isto é, que conecta Deus e criação, ou seja, um conceito unívoco de uma determinação ou perfeição como de "sabedoria"48. A propósito, "todos os mestres e teólogos", mesmo que devessem protestar verbalmente, parecem admitir tal conceito unívoco, pois eles todos estão em concordância que os "conceitos metafísicos" como bondade, verdade e sabedoria, os quais Duns Scotus designa também como perfeições puras, dado

43 Cf. DUNS SCOTUS, Ordinatio I d. 3 p. 1 q. 1-2 80-82, ed. Vat. III: 54-56; ib. q. 3 n. 133, ed. Vat. III: 82; ib. I d. 2 p. 1 q. 1-2 n. 31, Vat. II: 142-143; Lectura I d. 3 p. 1 q. 1-2 n. 69, ed. Vat. XVI: 250. Sobre a via divisionis como método da metafísica, cf. KRAUS, J. Die Lehre des Joh. Duns Scotus von der natura communis, Freiburg: Studia Friburgensis, 1927, p. 136.

44 Cf. DUNS SCOTUS, Lectura I d. 3 p. 1 q. 1-2 n. 76, ed. Vat. XVI: 253.

45 Cf. DUNS SCOTUS, Ordinatio I d. 3 p. 1 q. 3 n. 135, ed. Vat. III: 84.

46 Cf. DUNS SCOTUS, Lectura I d. 3 p. 1 q. 1-2 n. 21, ed. Vat. XVI: 232.

47 Cf. DUNS SCOTUS, Ordinatio I d. 2 p. 1 q. 3 n. 80-82, ed. Vat. II: 241.

48 Cf. DUNS SCOTUS, Ordinatio I d. 3 p. 1 q. 1-2 n. 39, ed. Vat. III: 26s. 
que a eles limitação e, com isso, imperfeição não advêm em si, mas só em concomitância, se aplicam a Deus sob exclusão das imperfeições que condicionam a criação ${ }^{49}$.

A univocidade se relaciona, segundo Scotus, com todas as determinações transcendentais. Afinal, transcendentais são aquelas determinações que advêm ao ente ainda antes da divisão em categorias, e assim também antes da diferenciação em finito e infinito. "O que é comum a Deus e à criatura, esse é tal que se atribui ao ente na medida em que ele é indiferente ao finito e ao infinito". De tal tipo, porém, não são apenas as determinações simplesmente convertíveis com o ente, como uno, verdadeiro e bom, mas também as determinações disjuntivas como ato e potência, necessário e possível, entre outras ${ }^{50}$.

Da univocidade do conceito de ser, contudo, ainda se pode falar numa outra perspectiva. Os scotistas, imediatamente após Scotus, colocaram a pergunta se 0 conceito de ente é também unívoco no sentido de que significa um comum ao ente real e ao meramente pensado ${ }^{51}$. É o ente um conceito transcendental ou - como se dizia então na escolástica hispânica - um conceito super-transcendental: eis a pergunta simplesmente crucial para a história posterior da repercussão do scotismo, a qual, passando pela filosofia da escola (Schulphilosophie) alemã até Kant e Heidegger, estende-se de fato até a interpretação histórica de Scotus nos nossos dias. Com respeito ao próprio conceito scotista do ser, a pergunta deve ser respondida inequivocamente. Scotus enfatizou em todas as fases do seu pensamento que não há nenhum conceito comum unívoco entre o ens reale e o ens rationis, isto é, entre o lógico-possível e o lógico-impossível ${ }^{52}$. O conceito de ser de Duns Scotus é, por isso mesmo, unívoco em sentido transcendental, mas não em sentido supertranscendental. A pesquisa moderna, que descobriu o significado da ontologia scotista para o curso posterior da história da filosofia, freqüentemente não atentou para essa distinção, atribuindo a Scotus, a partir de posições tardias, por exemplo, a partir das idéias de Kant sobre o objeto em absoluto, um conceito de ser unívoco e super-transcendental, o qual Scotus não possui ${ }^{53}$.

49 Cf. DUNS SCOTUS, Lectura, I, d. 3, p. 1, q. 1-2, n. 29, ed. Vat. XVI: 233. Sobre a diferença entre as perfeições puras e aquelas necessariamente limitadas, cf. Duns Scotus, Ordinatio, I, d. 2, p. 1, q. 3, n. 187, ed. Vat. II: 241.

50 Cf. DUNS SCOTUS, Ordinatio, I, d. 8, p. 1, q. 3, n. 113-115, ed. Vat. IV: 205-207; cf. Ordinatio, II, d. 1, q. 4-5, n. 231, ed. Vat. VII: 116.

51 Sobre esse novo significado do conceito de univocidade, cf. KNEBEL, S. K. "Art. Univozität; univok", in: J. Ritter; K. Gründer; G. Gabriel (Hrsg.), Historisches Wörterbuch der Philosophie, Basel: Schurabe, Band 11, 2001, p. 228, e KOBUSCH, T. "Das Seiende als transzendentaler und supertranszendentaler Begriff", in: L. Honnefelder et alii (eds.), John Duns Scotus - Metaphysics and Ethics. Leiden: E. J. Brill, 1996, p. 345-366.

52 Cf. DUNS SCOTUS, Lectura, I, d. 29, q. 3, n. 4, ed. Vat. XVII: 395: "sed enti reali et enti rationis non est aliquid commune univocum". Cf. DUNS SCOTUS, Ordinatio, I, d. 29, q. un., n. 3, ed. Vat. VI: 166; Reportata parisiensia, I, d. 29, q. un., n. 10, ed. Vivès XXII: 369: "[...] licet posset abstrahi unus conceptus univocus a Deo et creatura, non tamen a re rationis et re reali, [...]".

53 É mérito de GILSON, E. L'Être et l'Essence, Paris: Vrin, 1948, ter feito referência à história de repercussão da doutrina do ser aviceniana-scotista - seguramente sob os presságios da ominiabrangente ontologia do ato de Tomás de Aquino - até Suarez, Chr. Wolff e Kant. Os trabalhos de HONNEFELDER, L. em especial Scientia transcendens. Die formale Bestimmung der Seiendheit und Realität in der Metaphysik des Mittelalters und der Neuzeit (Duns Scotus - Suarez-Wolff-Kant-Peirce). Hamburg: Meiner, 1990, 


\subsection{Metafísica e teologia}

Sem dúvida, a metafísica forma o centro da doutrina filosófica de Duns Scotus. Ainda que o doctor subtilis faça todo esforço para distinguir a sua concepção metafísica daquela de Henrique de Gand, ele jamais consegue sair de todo da sombra dessa grande alternativa à ontologia do ato de Tomás de Aquino. Isso o conceito de ente revela de modo muito claro.

A pergunta pelo objeto da metafísica fora respondida de modo extremamente diferente pelos dois mais famosos pensadores árabes. Avicena tinha defendido a tese de que 0 ente enquanto ente é este objeto, Averróis, em contrapartida, tinha posto a clássica contra-tese de que Deus e as inteligências são o tema da metafísica, segundo o entendimento aristotélico. Os grandes pensadores dos séculos XIII-XIV, Tomás de Aquino, Henrique de Gand, Mestre Eckhart e assim também Duns Scotus, todos eles, assumiram a visão de Avicena. Contudo, todos tentaram também fazer jus à pretensão de Aristóteles, a saber, de conceber a metafísica não somente como ontologia, mas também como teologia, como scientia divina.

Tomás de Aquino o fizera na medida em que atribui a investigação dos princípios e causas do objeto também à competência da metafísica, a qual, por isso mesmo, faz justiça ao nome de "Filosofia Primeira". Duns Scotus diferencia, nesse sentido, justamente assim como Tomás de Aquino expôs isso no famoso Proêmio do seu comentário à Metafísica, entre o objeto e o fim da metafísica. Objeto da metafísica pode ser somente o ente em universal ou o ente como tal. O fim da metafísica, porém, tem de ser o conhecimento do ente supremo $0^{54}$. Duns Scotus abandonou, contudo, o pensamento fundamental da metafísica tomasiana - nisso em seguimento inequívoco a Henrique de Gand -, porque "do ente enquanto é ente, o qual é tido como objeto da metafísica, não há quaisquer princípios"55. Manifestamente, a saber, quem busca por princípios externos ou internos do ente enquanto ente - e nisso ele quer dizer o sentido reduplicativo desta expressão - pressupõe o caráter do ser-causado deste ente. Princípios ou primeiras causas do ente enquanto ente em sentido reduplicativo, portanto, de cada ente, só podem por isso mesmo ser objeto da metafísica, para Scotus, na medida em que - em termos de teoria do conhecimento - designam as primeiras proposições imediatas, por conseguinte - ontologicamente - as propriedades do ente demonstradas através dos princípios, isto é, as communissima, portanto, as determinações transcendentais ${ }^{56}$. Em verdade, contudo, a metafísica

seguem, em princípio, esse caminho previamente indicado. Dado que neste trabalho, como também em Ens inquantum ens. Münster: Aschendorff, 21989, a diferença entre o sentido transcendental e o supertranscendental do conceito de ente não é reconhecido, o ente geral é apresentado como uma entidade formal antes da distinção de ens reale e ens rationis. Cf. HONNEFELDER, L. Ens inquantum ens, p. 430: "antes de todo ser-pensado"; também p. 432: "o qual (...) é 'anterior' ao ser-real extramental e ao serpensado". Semelhantemente idem, Duns Scotus. München: Beck, 2005, p. 81. Com efeito, o conceito de ente sempre significa, em Scotus, somente a determinação formal do ens reale.

54 Cf. DUNS SCOTUS, Quaestiones super libros Metaphysicorum Aristotelis, I, q. 1, n. 160, St. Bonaventure (N. Y.) 1997, OP III: 71.

55 Cf. DUNS SCOTUS, Ordinatio, prol., p. 3, q.1-3, n.191, ed. Vat. I: 128. Cf. Henrique de Gand, Summa, a.19, q.1.

56 Cf. DUNS SCOTUS, Quaestiones super libros Metaphysicorum Aristotelis, I, q. 1, n. 80-82, OP III: 42-43; Ordinatio, prol., p. 3, q. 1-3, n. 191, ed. Vat. I: 128; Lectura, prol. p. 2 q. 1-3 n. 95, ed. Vat. XVI : 34. 
considera o ente como ente em sentido especificante, isto é, como entidade mesma ou como uma "qüididade absoluta" 57 , bem como as determinações gerais que a seguem imediatamente, isto é, uno, verdadeiro e bom, ao lado disso também os transcendentais disjuntivos, como, por exemplo, possibilidade e realidade, e finalmente as assim chamadas perfeições puras como sabedoria, liberdade, vida etc ${ }^{58}$. Uma vez, porém, que todas as ciências particulares pressupõem o saber desses objetos mais gerais, sem poder em verdade tratá-los tematicamente, tem de haver uma ciência única que tem como objeto essas communissima, sem as quais 0 particular não pode ser conhecido, isto é, a metafísica, que é a ciência dos transcendentais ${ }^{59}$.

Com a doutrina dos transcendentais, porém, a teologia filosófica está conectada intimamente. "Esse tanto é certo, Deus é um objeto da metafísica, pois Ele é 'considerado nesta ciência no modo mais perfeito que é possível que seja considerado por qualquer ciência adquirida naturalmente'" 60 . A doutrina dos transcendentais se torna como que, de si mesma, uma doutrina de Deus, na medida em que vê as determinações transcendentais a posteriori, isto é, como efeito de uma causa. A pergunta que se põe, a saber, com respeito a essas "propriedades metafísicas" é como elas, então, podem ser atribuídas ao ente como tal, quando não são operadas por uma primeira causa ${ }^{61}$. "Deus pode, de acordo com isso, ser provado como causa necessária das propriedades que são atribuídas necessariamente a todo ente" 62.0 intelecto humano, no presente estado, está em condições de conhecer a Deus como o ente infinito ou como o bem supremo, ou sob outras propriedades, na medida em que, quando conhece o ente determinado como algo branco ou como um pedra, desconsidera essas determinações particulares e conhece a determinação geral do ente, e assim também o sumo ou o bem em absoluto, abstraindo desse ou daquele determinado, até que, finalmente, ele conecta essas determinações gerais abstraídas das coisas criadas com Deus, como o ente supremo ou o bem supremo.

A partir daí "podemos conhecer a Deus em geral"63. O "primeiro objeto" da metafísica não é, a partir disso, Deus, mas somente ela como a "mais excelente" ciência entre aquelas naturalmente conhecíveis pode tematizar a primeira causa de todas as propriedades metafísicas ${ }^{64}$. Não pode de modo algum ser objeto de dúvida que Duns Scotus anda pelo mesmo caminho do conhecimento de Deus que Henrique

57 Cf. DUNS SCOTUS, Reportata parisiensia, I, d. 21, q. un., n. 8, ed. Vivès XXII: 258.

58 Sobre a quatripartição dos transcendentais, cf. WOLTER, A. B. The Transcendentals and their Function in the Metaphysics of Duns Scotus, St. Bonaventure (N. Y.): The Franciscan Institut, 1946, p. 181.

59 Cf. DUNS SCOTUS, Quaestiones super libros Metaphysicorum Aristotelis prol. n. 18, OP III: 9: "[...] quia est de transcendentibus"; I, q. 1, n. 72, OP III: 39; Lectura, prol., n. 40, ed. Vat. XVI: 17.

60 Cf. DUNS SCOTUS, Ordinatio, prol., q. 3, n. 20, ed. Vivès VIII: 171a. Cf. WOLTER, A. B. op. cit., p. 179.

61 Cf. DUNS SCOTUS, Ordinatio, prol., p. 3, q. 1-3, n. 194, ed. Vat. I: 131; Quaestiones super libros Metaphysicorum Aristotelis, VI, q. 4, n. 3, St. Bonaventure (N. Y.) 1997, OP IV: 85; Reportata parisiensia, prol., q. 3, a. 1, ed. Vivès XXII: 46b-47a).

62 Cf. GILSON, E. Johannes Duns Scotus. Einführung in die Grundgedanken seiner Lehre, übertragen von W. Dettlof., Düsseldorf: Schuann, 1959, p. 84.

${ }^{63}$ Cf. DUNS SCOTUS, Lectura, I, d. 3, p. 1, q. 1-2, n. 56, ed. Vat. XVI: 246.

64 Cf. DUNS SCOTUS, Ordinatio, prol., p. 3, q. 1-3, ed. Vat. I: 130-131. 
de Gand havia, com remissão a Avicena, introduzido: pelos transcendentais até Deus. Isso caracteriza a metafísica medieval, como um todo, no sentido de que ela não é diretamente e sem mediações uma teologia filosófica, mas somente num modo mediado pela ontologia ${ }^{65}$. Isso já vale - e sobretudo - para a metafísica de santo Tomás de Aquino: "teologia filosófica" - um conceito que, em verdade, é utilizado pela primeira vez pelo próprio Tomás de Aquino ${ }^{66}$ - "é possível para Tomás de Aquino somente como a doutrina do ens commune, cuja causa última é Deus" ${ }^{67}$. Porém, isso é válido também para o conhecível naturalmente de Deus mediado pela doutrina dos transcendentais, portanto, para a metafísica na medida em que é teologia filosófica, em autores como Henrique de Gand, Duns Scotus e outros, entre eles também Mestre Eckhart, os quais seguiram o novo caminho de Avicena ${ }^{68}$.

Traduzido do alemão por Roberto Hofmeister Pich

65 HONNEFELDER, L. Duns Scotus, p. 55, separou, com respeito à metafísica medieval, a "onto-teologia" e a "ontologia", designando a metafísica de Scotus como a "primeira tentativa histórica de realizar a metafísica como ontologia". Com efeito, ou as metafísicas de Tomás de Aquino e de Henrique de Gand já são tais tentativas ou então a metafísica de Scotus é o que todas as interpretações da metafísica de Aristóteles desde Alexandre de Afrodísias sempre foram e ainda por muito tempo depois de Scotus permanecerão sendo: a saber, onto-teologia.

66 Cf. TOMÁS DE AQUINO, In Boeth. De Trinitate, p.3, q.5, a. 4, c. 4.

67 Cf. OEING-HANHOFF, L. "Ens et Unum convertuntur. Stellung und Gehalt des Grundsatzes in der Philosophie des hl. Thomas von Aquin". BGPhThMA, 37 (1953), p. 12.

68 Sobre o "novo caminho" do conhecimento de Deus proposto pela primeira vez por Henrique de Gand, ver o artigo correspondente de PEGIS, A. C. "Toward a New Way to God: Henry of Ghent". Mediaeval Studies, 30 (1968), p. 226-247; 31 (1969), p. 93-116; 33 (1971), p. 158-179. Também AERTSEN, J. A. "Meister Eckhart: eine außerordentliche Metaphysik". Recherches Théologie Philosophie Médiéval, 66 (1999) p. 1-20, fala de um "lugar extraordinário" que a metafísica dos transcendentais assume em Mestre Eckart, e faz remissão (p. 17) a semelhanças com Duns Scotus. Por outro lado, ele reconhece na nova concepção de transcendentalidade em Scotus uma "virada" na doutrina dos transcendentais (ver AERTSEN, Jan. "Die Umformung der Metaphysik. Das mittelalterliche Projekt der Transzendentalien", in: J. BRACHTENDORF (Hrsg.). Prudentia und Contemplatio. Ethik und Metaphysik im Mittelalter: Festschrift für G. Wieland. Paderborn u. a.: Schöningh, 2002, p. 89-106, especialmente p. 101s.). Com efeito, mesmo que as concepções dos transcendentais em Henrique, Mestre Eckhart e Duns Scotus possam ser diferentes nos detalhes, nisso elas são unânimes: o caminho leva dos transcendentais a Deus. 